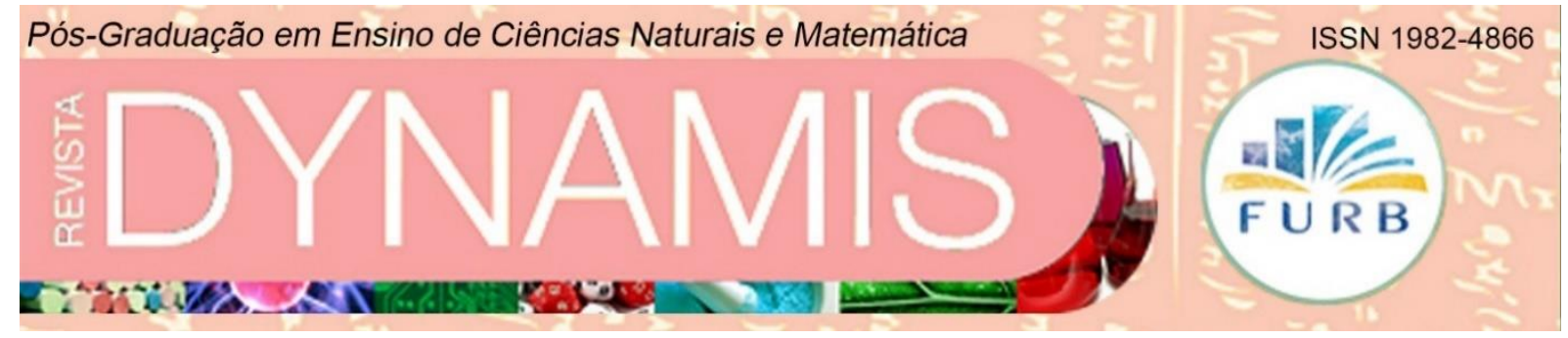

\title{
AGRO É TECH, AGRO É POP? \\ RACIONALIDADES EXPRESSAS POR PROFESSORES DO ENSINO TÉCNICO AGRÍCOLA BRASILEIRO
}

Agro is tech, agro is pop?

Rationalities expressed by teachers of brazilian agricultural technical education

Leila Cristina Aoyama Barbosa Souza

Doutora em Educação Científica e Tecnológica

Escola Técnica Estadual de Educação Profisssional e Tecnológica de Mato Grosso aoyama.leila@gmail.com

Carlos Alberto Marques

Doutor em Ciências Químicas

Programa de Pós-graduação Educação Cientifica e Tecnológica - PPGECT

Universidade Federal de Santa Catarina

carlos.marques@ufsc.br 


\title{
Resumo
}

Este trabalho busca identificar as compreensões de professores do ensino técnico agrícola sobre o uso de agrotóxicos nas atividades agrícolas. É uma pesquisa qualitativa e descritiva na qual se efetuou entrevistas semiestruturadas com onze professores formadores de técnicos agrícolas em cursos fundamentados na perspectiva agroecológica ou do agronegócio de cinco instituições públicas de educação profissional (duas mato-grossenses e três catarinenses). Pelo uso da Análise Textual Discursiva e a partir de uma situação exemplar de contexto agrícola - a contaminação de Lucas do Rio Verde/MT por conta da pulverização de agrotóxicos evidenciou-se a expressão da racionalidade instrumental nas compreensões dos professores. Entre os formadores de cursos técnicos em Agricultura e Agropecuária prevaleceu a compreensão do fato como um acidente devido a falhas técnicas, denotando a crença no uso seguro de agrotóxicos e alinhamento com a racionalidade instrumental. Porém, observou-se que tais sujeitos podem se encontrar em uma transição de racionalidades: ora manifestando discursos impregnados de racionalidade instrumental, ora falas que transparecem a racionalidade socioambiental. Por sua vez, os formadores de técnicos em agroecologia demonstraram um pensamento crítico que questiona o uso desses produtos químicos e põe em dúvida as certezas científicas que apontam para a segurança de tal utilização.

Palavras chave: Ciência-Tecnologia-Sociedade. Educação Crítica. Agrotóxicos.

\begin{abstract}
This work aims to identify the understanding of agricultural technical education teachers about the use of pesticides in agricultural activities. It is a qualitative and descriptive research in which semi-structured interviews were conducted with eleven teachers training agricultural technicians in courses based on the agroecological or agribusiness perspective of five public institutions of professional education (two schools in Mato Grosso and three schools in Santa Catarina). Through the use of Discursive Textual Analysis and from an exemplary situation of agricultural context - the contamination of the municipality of Lucas do Rio Verde/MT due to the spray of pesticides - the expression of instrumental rationality in teachers' understandings was evidenced. Among the trainers of technical courses in Agriculture and Agriculture prevailed the understanding of the fact as an accident due to technical failures, denoting the belief in the safe use of pesticides and alignment with instrumental rationality. However, it was observed that such subjects may find themselves in a transition of rationalities: sometimes manifesting discourses impregnated with instrumental rationality, or lines that transcend socioenvironmental rationality. In turn, trainers of agroecology technicians have demonstrated critical thinking that questions the use of these chemicals and calls into question the scientific certainties that point to the safety of such use.
\end{abstract}

Keywords: Science-Technology-Society. Critical Education. Pesticides. 


\section{INTRODUÇÃO}

Nessas primeiras décadas do século XXI, as transformações da sociedade pela revolução tecnológica são explicitamente perceptíveis. Ao mesmo tempo em que observamos o avanço do mundo globalizado, da velocidade com que as informações alcançam a todos por meio da internet e da evolução de produtos industrializados e processos tecnológicos cada vez mais eficientes; percebe-se a necessidade da participação social nas decisões que dizem respeito ao bem comum coletivo. Diversas questões sociocientíficas dizem respeito a essa situação, a exemplo, a decisão sobre a regulamentação de rótulos de produtos alimentícios que apresentam organismos geneticamente modificados (transgênicos) em sua constituição.

A educação apresenta papel crucial na formação da consciência crítica dos sujeitos a partir da apreensão de conhecimentos científicos (CHASSOT, 2003). O empoderamento por meio do conhecimento permite a melhor participação da sociedade nas decisões do Estado relacionadas a questões que apresentam riscos ou prejuízos ao meio ambiente e à saúde humana. Além de este papel ser fundamental na educação básica e ensino superior, desde 2003 temos acompanhado a expansão da educação profissional e tecnológica no Brasil (PACHECO, 2011). Isto significa outro ambiente educacional em que se deve estimular, além da formação para uma profissão, a formação da consciência crítica dos sujeitos. Consciência esta, que permita reconhecer o ser humano como um ser histórico, a realidade e suas relações com as diversas dimensões (FREIRE, 2005) e o papel da sociedade na construção da ciência e tecnologia.

Dentre os diversos cursos da educação profissional e tecnológica, nossa investigação se aprofunda na formação do técnico agrícola. Esse profissional vivencia, especialmente nos estados brasileiros de elevada produção de grãos, um mundo agrícola economicamente promissor de um lado e altamente problemático por outro. Se de um lado o avanço do agronegócio reforça a importância do setor primário na economia nacional, desencadeando um processo que vai desde a produção de alimentos até a distribuição; por outro, o técnico agrícola se defronta cada vez mais com danos ambientais decorrentes da chamada "agricultura em larga escala".

Temáticas relacionadas às atividades agropecuárias e agronegócio no Brasil apresentam tamanho grau de polêmica que, atualmente, tem sido veiculado a campanha televisa "Agro é tech, agro é pop, agro é tudo ${ }^{1}$

Com o intuito de difundir as benfeitorias deste setor produtivo para o desenvolvimento socioeconômico do país. Alguns autores têm levantado suspeita sobre a razão deste enaltecimento, pois é certo que o setor movimenta a economia do país, porém é responsável por problemas ambientais e problemas sociais - enriquecimento de pequenos grupos e estímulo aos latifúndios (ARANTES, 2017). Campanhas desse tipo apresentam claramente os interesses do mercado e tendem a demonstrar a ideologia capitalista como sendo a melhor ou única opção (LAMOSA; LOUREIRO, 2014).

Neste trabalho - que é um recorte de pesquisa de doutorado (SOUZA, 2016), apresentamos os resultados de uma pesquisa empírica referente às compreensões de professores do ensino técnico agrícola mato-grossense e catarinense sobre o uso de agrotóxicos em atividades agrícolas brasileiras. A partir dessas compreensões foi possível diagnosticar as

\footnotetext{
${ }^{1}$ A Campanha "Agro é Tech, Agro é Pop, Agro é tudo", concebida pelas gerências de Marketing e de Comunicação da Rede Globo, tem duração de dois anos (2016-2018). A cada quinze dias, um novo tema é apresentado ao público. Até agora, já foram abordados temas como: frango, café, milho, arroz, laranja, flores, algodão, cacau, maçã, feijão, banana, cana de açúcar, uva e transporte.
} 
diversas racionalidades que permeiam as práticas docentes e influenciam o ensino desta modalidade e que, certamente, norteiam as práticas dos professores de modo geral, independentes do nível educacional em que atuam. Juntamente com tais dados coletados em 2015 (período anterior ao lançamento da campanha midiática em prol do agronegócio), aproveitamos o momento para atualizar nossa reflexão ao discutir brevemente sobre as relações Ciência-Tecnologia-Sociedade que se impõem neste início de século XXI e o papel do professor e da educação frente ao cenário atual.

\section{AGRO É TECH: O INTENSO USO DE AGROTÓXICOS NAS ATIVIDADES AGRÍCOLAS BRASILEIRAS}

Nos últimos anos, o Brasil tem sido citado como um dos maiores consumidores mundiais de agrotóxicos (PORTO; SOARES, 2012). As explicações que se replicam para justificar tal fato são: as grandes áreas de produção agrícola do país, a busca pela alta produtividade e a elevada adoção de sementes transgênicas - que exigem produtos químicos específicos para seu desenvolvimento (MIRANDA et al., 2007).

Segundo legislação federal, agrotóxicos são produtos e agentes de processos físicos, químicos ou biológicos, destinados a prevenir, destruir ou repelir, direta ou indiretamente, qualquer forma de agente patogênico ou de vida animal ou vegetal, que seja nociva às plantas e animais úteis, bem como as substâncias e produtos empregados como desfolhantes, dessecantes, estimuladores e inibidores de crescimento (BRASIL, 2002).

Peres, Moreira e Dubois (2003) explicam sobre o uso de diferentes termos para falar destes produtos: "defensivos agrícolas" ou "pesticidas" (para as indústrias químicas e empresas que os comercializam); "remédio" (para vendedores ligados às indústrias, que assim os apresentam aos agricultores); "veneno" (para os agricultores que desconfiam ou já vivenciaram os efeitos nocivos destes produtos à saúde e ambiente). Os autores destacam ainda que, enquanto as línguas inglesa e espanhola utilizam o termo pesticides e plaguicidas, respectivamente, para denominar este grupo de produtos químicos, o Brasil é um dos poucos países que adota um termo que demonstra claramente "o caráter prejudicial destas substâncias, visualizado no radical "tóxico"' (p. 23). Assim, tal como esses pesquisadores, preferimos o uso do termo agrotóxicos visto que, além de melhor caracterizar as substâncias que constituem tal universo, conscientiza o leitor aos possíveis efeitos nocivos inerentes ao uso delas.

Em relação ao número de produtos agrotóxicos registrados em nosso país, Silveira e Antoniosi Filho (2013), a partir de levantamento bibliográfico, conferiram até o ano de 2010, a existência de 880 produtos formulados a partir de 508 ingredientes ativos. Estes agrotóxicos podem ser inseticidas, fungicidas, herbicidas, nematicidas, acaricidas, rodenticidas, moluscidas, formicidas e tantos outros venenos utilizados pelo setor agropecuário e alguns também para uso doméstico. A fim de atualizar tais informações, nossa busca recente na base de dados do Sistema de Agrotóxicos Fitossanitários (AGROFIT) indicou, no início de 2016, o registro de 381 ingredientes ativos, que, combinados, resultam em 1.809 formulações de agrotóxicos (SOUZA, 2016). Esses levantamentos bibliográficos realizados demonstram que, entre 2013 e 2016, houve a redução no número de ingredientes ativos de uso permitido no país, apontando para o banimento de alguns deles, em contrapartida, evidencia-se a ampliação da quantidade de produtos formulados - sinalizando, talvez, o elevado potencial dos procedimentos tecnológicos para a fabricação de produtos químicos cada vez mais específicos. 
Segundo o dossiê da Associação Brasileira de Saúde Coletiva (ABRASCO, 2015), das 50 substâncias mais pulverizadas nas lavouras brasileiras, 22 já foram banidas nos países da União Europeia. Enquanto isso, aqui, desde 2008, apenas 14 delas estão em processo de reavaliação pela ANVISA ${ }^{2}$. Esse fato pode demonstrar divergências entre o Brasil e os países da Europa, por exemplo, para adoção de medidas precaucionárias sobre o uso de alguns tipos de agrotóxicos. O endossulfam, agrotóxico amplamente utilizado em lavouras de café, algodão, soja e cacau, foi proibido na Europa nos anos de 1990 (CINTRA, 2013). A suspeita era de se tratar de um provável desregulador endócrino (substâncias que podem alterar a função do sistema hormonal no corpo) e ocasionar danos irreparáveis ao sistema reprodutivo humano. Somente em julho de 2013 tal ingrediente ativo foi banido em nosso país.

\section{Figura 1 - Relação dos valores de comercialização de agrotóxicos e total de área plantada no Brasil (2000-2012)}

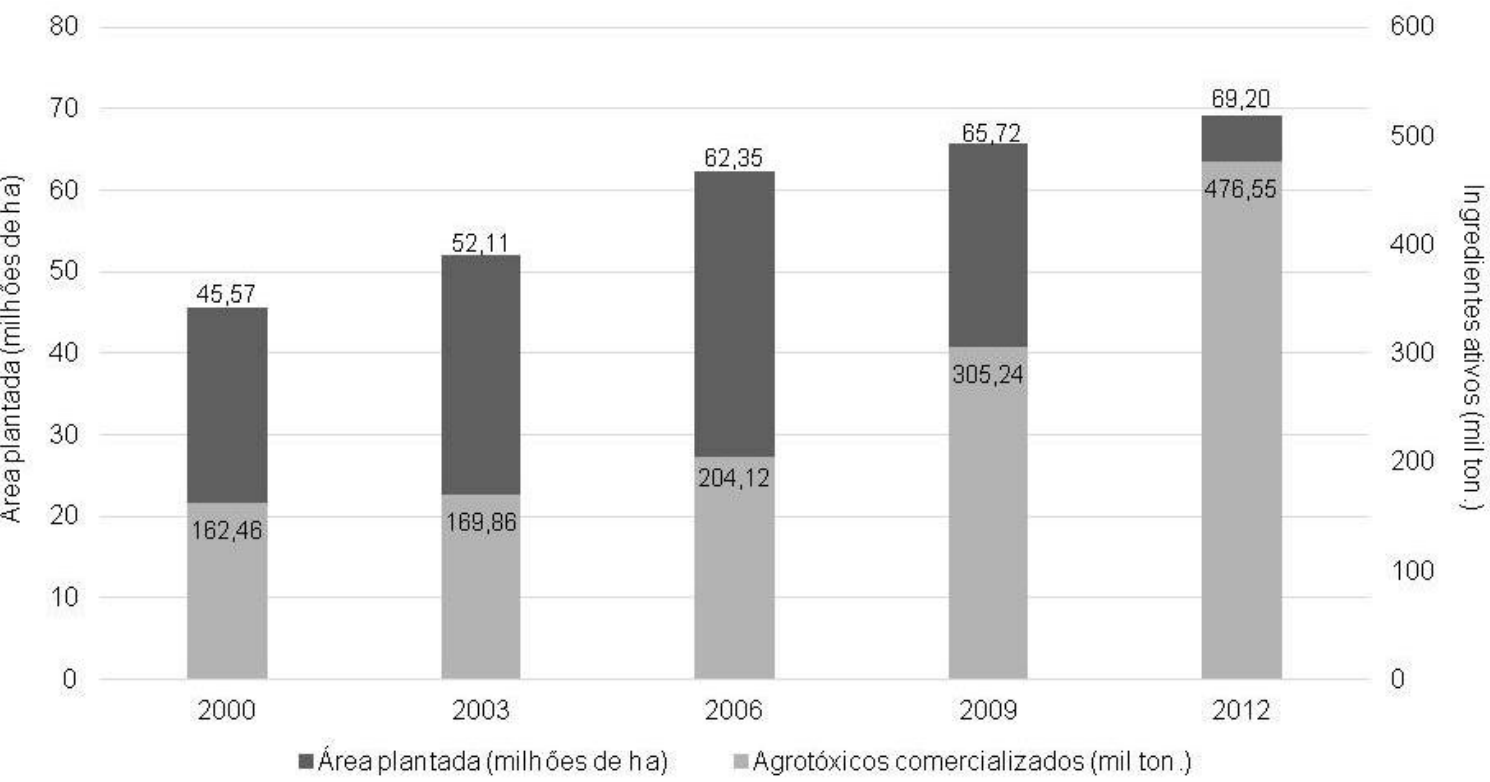

Fonte: Adaptado de Souza (2016, p. 189)

A Figura 01 apresenta, graficamente em seu eixo y secundário (à direita), dados relativos à comercialização de agrotóxicos no Brasil a cada triênio, entre os anos 2000 e 2012. Observase que desde 2003 houveram aumentos consideráveis nas vendas de produtos agrotóxicos (saltando de 169,8 mil para cerca de 204,1 mil toneladas de ingredientes ativos). E a cada triênio posterior, constata-se que o aumento dos números representou um acréscimo de cinquenta por cento destas quantidades.

Ingenuamente poderia se associar o aumento de venda/consumo de agrotóxicos ao aumento da área produtiva do país e sempre relacionando o uso destes produtos, bem como de

\footnotetext{
2 Dos 14 agrotóxicos em processo de reavaliação, quatro deles já foram proibidos (cihexatina e tricloform). O metamidofós foi retirado do mercado desde junho de 2012 e o endossulfam em junho de 2013 . "O fosmete e o acefato tiveram seus usos restringidos, apesar dos achados toxicológicos serem indicativos de banimento. Outros dois já concluíram a consulta pública de revisão (forato e parationa-metílica) e os demais já tiveram suas notas técnicas de revisão concluídas pela Fiocruz: lactofem, furano, tiram, paraquat, glifosato, abamectina (ANVISA, 2008; 2012a; 2012b)" (ABRASCO, 2015, p. 53).
} 
outros insumos agrícolas, ao aporte tecnológico do setor agropecuário. No entanto, ao examinar tais valores, percebe-se que o incremento ocorre em proporções diferentes, conforme também se visualiza na figura.

No gráfico 1 o eixo y principal (à esquerda) representa a escala da área plantada de lavouras temporárias no Brasil. Observa-se que a área produtiva do país, entre os anos 2000 e 2012, obteve um aumento de aproximadamente cinquenta por cento, saltando de 45 para 69 milhões de hectares. Já o consumo de agrotóxicos quase triplicou nesse mesmo período (de 162 para 476 mil toneladas). $\mathrm{O}$ ano de 2006 sinaliza a mudança no comportamento da relação entre quantidade de agrotóxicos e área plantada uma vez que, entre 2000 e 2006, a relação era de aproximadamente $3,2 \mathrm{~kg}$ de agrotóxicos/hectare (ha). A partir de então surgiu um crescimento desta taxa: 4,6 kg/ha em 2009 e alcançando 6,8 kg/ha em 2012.

Uma possível explicação para tal incremento a partir de 2006 pode se relacionar à regulamentação dos transgênicos no Brasil, pela Lei de Biossegurança, que estabelece normas de segurança e mecanismos de fiscalização de atividades que envolvam organismos geneticamente modificados e reestrutura a Comissão Técnica Nacional de Biossegurança CTNBio (BRASIL, 2005). Embora haja registros da adoção de lavouras transgênicas desde 2003 no país, com 4,7 milhões de hectares cultivados, em 2006 este valor subiu para 11,6 milhões e ultrapassou mais de 37 milhões de hectares em 2012 (CÉLERES, 2013).

Sabemos que o cálculo da relação entre quantidade de agrotóxicos comercializados e área produtiva não é uma simples aritmética, pois os dados levantados quanto às vendas destes produtos, além de contemplar ingredientes ativos utilizados na pecuária brasileira, refletem a área plantada de lavouras temporárias das mais diversas culturas (por exemplo, abacaxi, milho, cevada e melão). Cada uma delas utiliza quantidades de agrotóxicos diferentes. $\mathrm{O}$ consumo médio de agrotóxicos (herbicidas inseticidas e fungicidas), em 2011, por exemplo, para a soja foi de 12 litros/ha; do milho, 6 litros/ha; do algodão, 28 litros/ha; da cana-de-açúcar, 4,8 litros/ha; das culturas cítricas, 23 litros/ha e do café, 10 litros/ha (ABRASCO, 2015). Tais quantidades chamam a atenção por se tratar de valores elevados e, por vezes, levantam algumas indagações (que pode não ser tão perceptível a todos): para onde vão esses agrotóxicos após sua aplicação? Para as plantas, que depois serão colhidas e consumidas? Que associação eles possuem com os compartimentos naturais (solo, lençol freático e ar)? Quais os riscos à saúde e ambiente inerentes desse uso? E qual seria o papel dos profissionais das áreas agrárias, como o técnico agrícola, diante de tais números e riscos?

Dagnino (2008), se apoiando em trabalhos de Andrew Feenberg, ressalta que a tecnologia, vislumbrada por uma concepção de adequação sociotécnica, exige uma postura engajada para a construção social e a internalização de valores que busquem o bem-estar coletivo. A tecnologia não pode ser entendida como um processo inexorável que sempre garante o bemestar humano. Por ser algo construído socialmente, não é neutra; apresenta interesses que podem estar beneficiando grupos específicos.

Desse modo, pensar nas consequências do uso de agrotóxicos nas atividades agrícolas brasileiras exige a adoção de racionalidades diferentes da racionalidade instrumental - que, por ser técnica, enxerga apenas a relação custo-benefício e meio-fim. Interessam-nos compreender o modo como os professores formadores de técnicos agrícolas concebem esse assunto. Por isso, a seguir, apresentamos os procedimentos metodológicos adotados e, posteriormente, os resultados da pesquisa empírica realizada.

\section{PROCEDIMENTOS METODOLÓGICOS}


Esta pesquisa apresenta uma abordagem qualitativa, por enfatizar mais o processo do que o produto, ter o ambiente natural - que é uma realidade complexa e contextualizada - como fonte direta de dados (predominantemente descritivos) e considerar os diferentes pontos de vista dos sujeitos que dela participam (LÜDKE; ANDRÉ, 1986). Quanto aos seus objetivos, classifica-se como descritiva por expor características de grupos específicos (GIL, 2010). Neste caso, o aprofundamento das compreensões de professores formadores de técnicos agrícolas sobre o uso de agrotóxicos nas atividades agrícolas. Para tanto, foram realizadas entrevistas semiestruturadas ${ }^{3}$ com onze professores de cinco instituições públicas de educação profissional (três catarinenses e duas mato-grossenses) que aceitaram o convite para participar da pesquisa.

A escolha das instituições destes dois estados brasileiros se relaciona ao local de trabalho da pesquisadora e ao de realização da tese de doutorado. As instituições catarinenses (aqui identificadas pelas letras B, C e D) apresentam cursos técnicos agrícolas com ênfase em agroecologia e outros para o agronegócio (Técnico em Agropecuária). Já as instituições matogrossenses (A e E) possuem cursos técnicos agrícolas cujo foco maior é as demandas do agronegócio (Técnico em Agricultura e Técnico em Agropecuária).

As entrevistas gravadas em áudio tiveram uma duração média, em geral, de quarenta minutos e versaram perguntas abertas sobre o caso do acidente rural de Lucas do Rio Verde/MT (PIGNATI, MACHADO, CABRAL, 2007), o uso de agrotóxicos nas atividades agrícolas brasileiras, o ensino dessa temática na formação do técnico agrícola e potencialidades da inserção do Princípio da Precaução no ensino deste profissional técnico. Neste artigo, apresentamos os resultados referentes às duas primeiras seções das entrevistas.

Após a realização das entrevistas, elas foram codificadas, transcritas para posterior análise e submetidas a cada sujeito entrevistado para aprovação. A Tabela 01 apresenta informações pertinentes a essa caracterização.

Tabela 1 -Caracterização das entrevistas concedidas por professores formadores de técnicos agrícolas

\begin{tabular}{ccccccc}
\hline \multirow{2}{*}{$\begin{array}{c}\mathbf{N}^{\mathbf{0}} \\
\text { Gravação }\end{array}$} & Codificação & Instituição & $\begin{array}{c}\text { Data da } \\
\text { entrevista }\end{array}$ & $\begin{array}{c}\text { Duração da } \\
\text { entrevista }\end{array}$ & & \multicolumn{2}{c}{ Transcrição } \\
\hline 1 & P-1 & C (SC) & $27 / 04 / 2015$ & $30: 20$ & 05 & 190 \\
produzinas (A4) & $\begin{array}{c}\text { Número } \\
\text { de linhas }\end{array}$ \\
\hline 2 & P-2 & C (SC) & $27 / 04 / 2015$ & $23: 39$ & 04 & 137 \\
3 & P-3 & D (SC) & $04 / 05 / 2015$ & $55: 32$ & 11 & 515 \\
4 & P-4 & D (SC) & $04 / 05 / 2015$ & $40: 25$ & 08 & 387 \\
5 & P-5 & E (MT) & $01 / 06 / 2015$ & $34: 17$ & 05 & 194 \\
6 & P-6 & E (MT) & $01 / 06 / 2015$ & $33: 36$ & 05 & 234 \\
7 & P-7 & E (MT) & $01 / 06 / 2015$ & $43: 23$ & 07 & 348 \\
8 & P-8 & A (MT) & $17 / 06 / 2015$ & $84: 58$ & 13 & 654 \\
9 & P-9 & B (SC) & $01 / 08 / 2015$ & $54: 46$ & 08 & 385
\end{tabular}

${ }^{3}$ Pesquisa submetida e aprovada pelo Comitê de Ética em Pesquisa com Seres Humanos, da Universidade Federal de Santa Catarina (CEPSH/UFSC), sob o número CAAE 44895815.6.0000.0121, atendendo a resolução CNS $466 / 2012$. 


\begin{tabular}{ccccccc}
\hline 10 & $\mathrm{P}-10$ & $\mathrm{~B}(\mathrm{SC})$ & $07 / 08 / 2015$ & $57: 20$ & 10 & 498 \\
\hline 11 & $\mathrm{P}-11$ & $\mathrm{~B}(\mathrm{SC})$ & $07 / 08 / 2015$ & $35: 35$ & 05 & 196 \\
\hline
\end{tabular}

Fonte: Dos autores.

Em relação à codificação dos sujeitos participantes para o tratamento analítico dos dados, utilizou-se a letra $\mathrm{P}$, significando professor, seguido de um número (1 a 11). Destacou-se, ainda, o curso (AEC para Agroecologia, APEC para Agropecuária e AGC para Agricultura) e o estado brasileiro de atuação de cada professor de maneira a identificar elementos que possam justificar seus pensamentos e posicionamentos. Assim, temos, por exemplo, o sujeito P-4-AEC/SC. Ainda a fim de preservar a identidade dos professores, não será feito a definição de gênero dos mesmos e nem serão mencionadas suas instituições de origem.

A partir do texto transcrito de cada entrevista e por meio da Análise Textual Discursiva obtiveram-se as unidades de sentido - unitarização -, que ao serem categorizadas categorização -, tornaram-se material para a construção dos metatextos (MORAES; GALIAZZI, 2006) que serão comunicadas a seguir.

\section{AGRO NÃO É POP: RACIONALIDADES EXPRESSAS POR PROFESSORES DO ENSINO TÉCNICO AGRÍCOLA}

A partir da leitura de uma notícia que descrevia a contaminação química do município mato-grossense de Lucas do Rio Verde/MT pela pulverização aérea de agrotóxicos em uma plantação, os professores formadores de técnicos agrícolas participantes da pesquisa, por meio de entrevistas semiestruturadas, manifestaram suas opiniões e compreensões sobre o uso de agrotóxicos nas atividades agrícolas brasileiras.

Transformando tais falas em corpus de análise, o uso da técnica metodológica da Análise Textual Discursiva (MORAES; GALIZAZZI, 2006) nos permitiu localizar quatro expressões de racionalidades: racionalidade instrumental, racionalidade econômica, racionalidade socioambiental e racionalidade crítico-emancipatória. A Figura 02 demonstra o resultado desse processo.

Figura 02 - Categorias emergentes da análise de falas dos professores referente ao uso de agrotóxicos nas atividades agrícolas brasileiras 


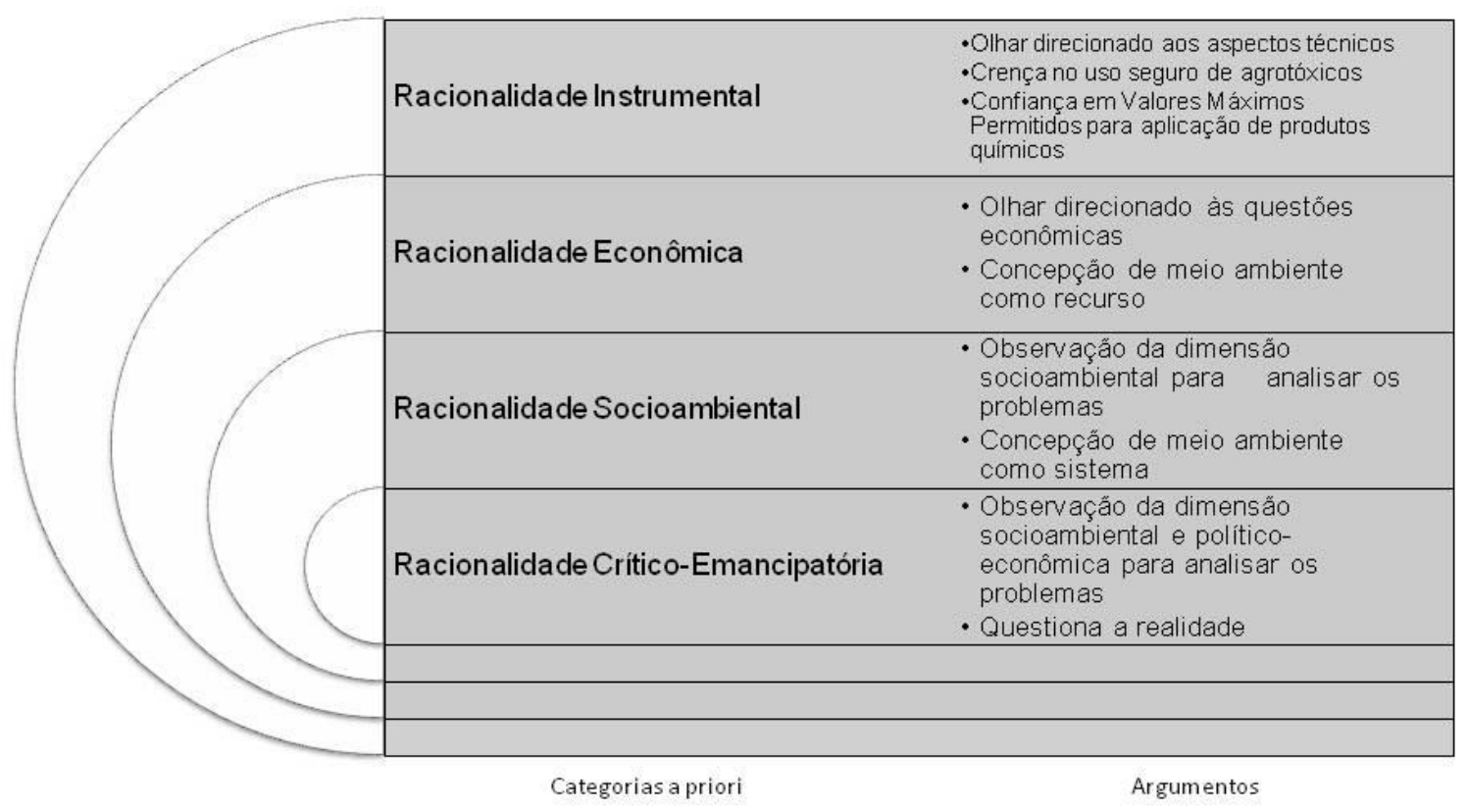

Fonte: Adaptado de Souza (2016, p. 115).

Questionados sobre a ocorrência do acidente rural de Lucas do Rio Verde/MT ${ }^{4}$, dos onze professores entrevistados, quatro conheciam sobre ele (P-5-APEC/MT; P-8-AGC/MT; P-10APEC/SC; P-9-AEC/SC). Os outros sete professores, apesar de não saberem sobre este fato em específico justificaram ter conhecimento da ocorrência de outros acidentes do tipo, em regiões próximas àquela.

Ao pensarem em possíveis causas da ocorrência do acidente rural de Lucas do Rio Verde/MT, com exceção de P-2, P-3 e P-9, professores de cursos Técnico em AEC/SC distintos, todos os demais (oito professores - dois do curso Técnico em Agroecologia e seis de cursos Técnico em Agropecuária/Agricultura) relacionaram-nas a aspectos técnicos - característica constituinte da racionalidade instrumental. As principais causas levantadas foram: a falta de treinamento dos trabalhadores (P-10 e P-11, ambos APEC/SC); a falta de planejamento quanto à utilização correta de equipamentos (P-4-AEC/SC; P-11-APEC/SC), a falta de assistência técnica ao agricultor (P-7, P-5, todos $\mathrm{APEC} / \mathrm{MT})$, a não observação das questões climáticas para a pulverização aérea (P-1-AEC/SC; P-8-AGC/MT) e a negligência do piloto (P-6EAPEC/MT).

Observa-se que as duas primeiras respostas supracitadas demonstram um olhar objetivo e direcionado apenas ao conhecimento técnico e científico, pouco observando outras dimensões, como, por exemplo, a ambiental e a social. Essas características evidenciam a racionalidade instrumental - razão esta que vê a técnica como um modo de "dominação (sobre

\footnotetext{
${ }^{4}$ Em março de 2006, após a pulverização aérea de agrotóxicos numa lavoura próxima ao rio do município de Lucas de Rio Verde/MT, ocorreu a contaminação do ambiente urbano. De acordo com Pignati, Machado e Cabral (2007), acredita-se que o produto químico em questão foi o herbicida paraquat (cujo ingrediente ativo é usado para secar as folhagens de soja, propiciando uma melhor colheita dos grãos). Testemunhas afirmaram que, naquele dia, havia formação de nuvens de chuva e de fortes ventos no local onde o avião realizava a pulverização. Com isso, a névoa fina que alcançou a cidade, e caiu sobre plantas, casas e solo, foi denominada "chuva de agrotóxicos", visto que visivelmente secou/queimou fragmentos das plantas por onde passou e pareceu ter desencadeado um surto de intoxicações agudas em crianças e idosos pelos sintomas de vômitos, náuseas e diarreia
} 
a natureza e sobre os homens), dominação metódica, científica, calculada e calculista" (MARCUSE, 1998, p. 132).

Tal racionalidade continua se expressando na fala dos professores quando eles pensam nas possíveis consequências e desdobramentos do acidente químico para o município, defendendo o cumprimento de normas técnicas:

Para a cidade em questão, primeiramente [existe por consequência] o impacto ambiental e na saúde das pessoas ao redor. Então, um impacto negativo sobre a incidência de doenças e a exposição gratuita, digamos assim, dos vizinhos a esses agentes químicos. Então, primeiro seria isso. O segundo, que se esperaria é que tivesse uma política da aplicação desses defensivos, desses agrotóxicos, mais bem elaborada e fiscalizada para que não voltasse a acontecer (P-1E-AEC/SC).

\begin{abstract}
Acho que todos os lados saem perdendo: as pessoas pela contaminação cumulativa no organismo por agrotóxicos; o ambiente, pois atingiu todo um ambiente que não seria o ambiente produtivo das pessoas [...]. E também um lado negativo técnico porque as pessoas estão fazendo aplicações de forma errada. E não respeitando os prazos, as condições climáticas, o vento, as condições de voo. No caso, em uma aplicação aérea, existem condições que precisam ser respeitadas. Então parece que estão fazendo tudo de uma forma errada, muitas vezes (P-11E-APEC/SC).
\end{abstract}

A crença de que a execução correta das normas para a aplicação dos agrotóxicos possa garantir o uso de agrotóxicos é algo aceito e difundido pelo próprio Estado que, por meio de suas instituições, apresentam legislações e regulamentos para tais assuntos. Essa situação encontra-se associada aos fundamentos da racionalidade instrumental; pois, sugere que as ações técnicas são capazes de solucionar qualquer problema existente, sem gerar dúvidas ou questionamento algum das pessoas. E, sendo esta racionalidade uma ciência que prima pelo exato (MARCUSE, 1998), outra característica a ela associada, que também é incentivada pelas legislações brasileiras e fortemente presente na cultura contemporânea, é a quantificação de valores máximos permitidos para uso de produtos químicos. Um exemplo desse tipo foi encontrado na fala de um professor ao afirmar que os seres vivos apresentam um limite de carga assimilativa de substâncias químicas, citando a dose letal (DL50):

\footnotetext{
Consequências? As consequências são as seguintes: vai desde..., porque esses produtos, uma vez ingerido.... Porque tem muitos produtos que o organismo se encarrega de, com o tempo, eliminar, né? Aí depende do produto que ele utiliza, né? Muitos ficam armazenados. Então, o uso contínuo desses produtos aqui, mesmo que você não está envolvido diretamente, com o tempo ele vai se acumulando até atingir aquela dose letal, né? Dose letal, que, futuramente, pode gerar uma série de consequências. Às vezes não para você, no momento, como câncer ou coisa parecida, mas seus descendentes podem até gerar filhos defeituosos (P-5- APEC/MT).
}

A DL50 indica a dosagem máxima de um produto químico capaz de matar cinquenta por cento dos organismos de uma população. Pela fala acima parece que, na compreensão do professor, apesar da consciência de que as substâncias químicas dos agrotóxicos podem provocar males aos organismos, o perigo maior para um ser vivo é quando se ultrapassa tal dosagem.

Atrelada a esses pensamentos típicos da racionalidade instrumental, por vezes encontrase a racionalidade econômica - que se caracteriza por submeter a natureza às leis do mercado e 
não abordar quaisquer discussões que enfatizem valores culturais ao ambiente (LEFF, 2006) e, sendo assim, pela compreensão de meio ambiente como um recurso a ser explorado. Essas compreensões puderam ser observadas no discurso dos professores quando estes ainda pensavam em possíveis consequências do acidente para o município de Lucas do Rio Verde/MT:

\begin{abstract}
Desde perda econômica para essas chácaras que estão em volta; perda da qualidade de vida; perda em termos de saúde dos produtores e das propriedades que, às vezes, tem pequena produção, que é agricultura familiar, que depende daquela produção. Então, a perda de qualidade de vida, tanto monetária, porque não vai poder ter aquele produto para poder oferecer e a parte da saúde dos produtores (P-2$\mathrm{AEC} / \mathrm{SC}$, grifo nosso).
\end{abstract}

Na fala supracitada, nota-se a prevalência da compreensão antropocêntrica onde há maior destaque à preocupação com o bem-estar humano do que com o ambiente. $\mathrm{E}$, mesmo indicando uma preocupação com os pequenos produtores e agricultores - que por ventura não faziam uso dos agrotóxicos e tiveram suas lavouras contaminadas pela localização próxima a área do acidente -, ainda se ressalta uma visão utilitarista de natureza como uma fonte a ser esgotada (SAUVÉ, 2005).

Sobre isto, Layrargues (1998) afirma que, sob influência da racionalidade econômica, os limites ecossistêmicos são ignorados e consideram-se fortemente os interesses econômicos. Os constantes entraves judiciais referentes ao banimento de determinados agrotóxicos no Brasil são outro exemplo de que tais interesses que acabam por direcionar as políticas públicas e ações governamentais.

Em julho de 2012, o Instituto Brasileiro do Meio Ambiente e dos Recursos Naturais Renováveis (IBAMA) divulgou um comunicado (DOU 19/07/2012, n. ${ }^{\circ} 139$, seção 3, p. 112) referente a proibição da aplicação por pulverização aérea de agrotóxicos que apresentassem os princípios ativos imidacloprido, clotianidina, fipronil e tiametoxam ${ }^{5} \mathrm{em}$ sua formulação. A proibição ocorreu a partir de estudos científicos em diversos países, sobre os efeitos adversos daqueles produtos às abelhas. Menos de três meses depois, devido às pressões dos produtores rurais, o mesmo órgão ambiental, em ação conjunta com o Ministério da Agricultura, emitiu um novo comunicado suspendendo temporariamente a proibição (DOU 03/10/2012, n. ${ }^{\circ} 192$, seção 1, p. 03). A justificativa para tal decisão foi "a necessidade de minimizar os impactos econômicos causados sobre determinadas culturas agrícolas decorrentes da adoção imediata das medidas previstas no Comunicado [anterior], em razão de contratos já celebrados e expectativas geradas para a safra 2012-2013" e "[...] o reconhecimento da SDA/MAPA [Secretaria de Defesa Agropecuária/Ministério da Agricultura] quanto à necessidade de um prazo para que os agricultores busquem alternativas aos produtos ou à forma de aplicação destes em algumas culturas" (BRASIL, 2012, p. 03). A pressão política dos representantes do setor agrícola derrubou de vez as medidas protetivas do IBAMA com o Projeto de Decreto Legislativo (PDC)

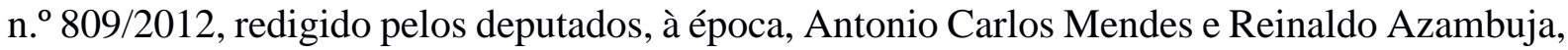
e aprovado, primeiramente pelo relator Duarte Nogueira e depois por unanimidade pela Câmara de Deputados brasileira.

O parecer do relator demonstrou-se favorável ao projeto ao afirmar: 1) "não haver razão para se adotar essa drástica restrição ao emprego de uma importante, segura e eficaz tecnologia

\footnotetext{
${ }^{5}$ Tais ingredientes ativos são utilizados como inseticidas para o controle de percevejos em culturas como arroz, algodão, cana-de-açúcar, trigo e soja.
} 
de controle de pragas das lavouras" - referindo ao uso da atividade de pulverização aérea na agricultura, 2) que a autarquia em questão "[...] exorbitou dos limites de delegação legislativa" (CÂMARA DOS DEPUTADOS, 2013, p. 03) e 3) sobre a impossibilidade da substituição da pulverização aérea pela terrestre em algumas regiões do país em razão de fatores como clima, solo, extensão e estágio de desenvolvimento da lavoura.

Todos os professores entrevistados, com exceção de P-8-AGC/MT, acreditam que o uso da aviação para a aplicação de agrotóxicos é problemático por conta da deriva ${ }^{6}$ que pode ocorrer e, consequentemente, do aumento da área passível de contaminação pelo produto. Esta compreensão já evidencia um processo de enfrentamento à racionalidade instrumental a partir de racionalidades alternativas (aqui denominada crítico-emancipatória). Nessas racionalidades outras dimensões, como histórica, cultural e estética, são consideradas e o meio ambiente não é compreendido apenas como um conjunto de elementos biofísicos, simplesmente tratados com objetividade e rigor (LOUREIRO, 2004). Foi possível evidenciar, nas compreensões dos professores, a observância de algumas destas outras dimensões, além da econômica, para compreender o acidente rural de Lucas do Rio Verde/MT.

A dimensão de mais simples associação que se apresentou nas falas dos professores uma vez que estava expressa no texto para leitura fornecida durante a entrevista - foi a ambiental. Todos os professores demonstraram preocupação com os possíveis impactos provenientes do mau uso ou uso excessivo de pulverizações de agrotóxicos em atividades agrícolas, indicando problemas de contaminações ambientais e intoxicações na saúde humana, conforme as seguintes falas:

Essa região de Lucas do Rio Verde, eu já ouvi falar de vários casos. Inclusive de casos de aumento da taxa de câncer. Então sempre tem alguma notinha falando do alto índice de poluição da cidade. Já teve várias matérias aí, que saiu nos jornais; várias matérias falando da cidade (P-5E-APEC/MT, grifo nosso).

\begin{abstract}
Desse acidente em si, não [ouvi falar]. Mas já é algo bem familiar para mim, esse tipo de prática de pulverizações de propriedades grandes, o qual já não se justifica mais pela via terrestre você ter necessidade do avião agrícola para poder fazer essas pulverizações e da deriva, que é o maior problema, pois o vento acaba levando esses pesticidas para atingir várias áreas. Contamina água, por deriva vai parar em propriedades vizinhas. Inclusive pessoas que não trabalham com a agricultura convencional e gostariam de trabalhar, por exemplo, com a agricultura agroecológica, não tem como porque a contaminação é grande (P-3-AEC/SC, grifo nosso).
\end{abstract}

Além disso, alguns dos sujeitos entrevistados (P-10-APEC/SC; P-3-AEC/SC) apresentaram explicitamente uma compreensão mais holística de dimensão ambiental ao vislumbrarem a cadeia ecológica envolvida e os efeitos em cascata decorrentes do processo de contaminação do ambiente, se aproximando de uma racionalidade socioambiental. Manifestando racionalidade semelhante, outro professor de instituição catarinense aponta:

Outro problema [da contaminação por produtos químicos em lavouras] seria o ligado ao meio ambiente, como: insetos predadores, ou seja, os inimigos naturais, seja de doenças ou de insetos, tanto dentro da lavoura quanto no entorno da lavoura, em áreas

\footnotetext{
${ }^{6}$ Conforme explicado anteriormente, a deriva trata-se do deslocamento horizontal que as gotas do produto químico aplicado na lavoura sofrem desde o seu ponto de lançamento até atingirem o ponto final - geralmente o solo ou a plantaalvo. Como a pulverização aérea corresponde é realizada em grandes áreas
} 
adjacentes, em áreas de refúgio, que também vão ser contaminados. Outra questão é a ligada à parte de contaminação de rios, contaminação de lagos, de captação de água, seja para a irrigação que vai contaminar, por exemplo, uma área que talvez não recebeu a pulverização direta, mas a água vai contaminada. Então, o produto, ele vai estar contaminado, entendeu? Outra questão é a aplicação dessa água, por exemplo, para animais e também para o uso na alimentação, para os homens, né? Pois o lençol freático vai estar contaminado. E também tem a questão direta, por exemplo, na questão de hortaliças; tem a questão que vão ser consumidas, por exemplo, pelos agricultores ou vão ser revendidas para pessoas na cidade. Ou seja, o alimento vai receber uma contaminação que não estava prevista. Por exemplo, um pé de alface que vai ser colhido amanhã, ou seja, hoje ele recebe uma contaminação. Então ele vai ser levado a um produto com período de carência de quinze dias, entendeu? Ou seja, não foi pulverizado na alface, mas esse agrotóxico veio, por exemplo, de uma contaminação aérea. E tem o prejuízo direto à saúde humana, por exemplo. Porque existem produtos que eles não causam náuseas, não causam vômitos imediatos, mas eles são bioacumulativos. Então, talvez o problema na saúde humana não é imediato. Alguns têm a contaminação imediata dependendo, é claro, da DL [dose letal], da dose do produto. Outros vão sendo bioacumulativos e, talvez, o problema para o agricultor vai ser anos ou décadas depois ou até mesmo na geração seguinte. É que existem casos hoje no Brasil de contaminação, de problemas na gestação e de desenvolvimento dos fetos (P-4-AEC/SC, grifo nosso).

Tal compreensão de meio ambiente é denominada por Sauvé (2005, p. 318) como concepção de meio ambiente - sistema, em que, pelo exercício do pensamento sistêmico reconhece-se "os vínculos existentes entre aqui e alhures, entre o passado, o presente e o futuro, entre o local e o global, entre as esferas política, econômica e ambiental, entre os modos de vida, a saúde e o meio ambiente". E todas as compreensões que expressaram esta concepção de meio ambiente foram de professores atuantes em cursos técnicos em Agroecologia de instituições catarinenses. Possivelmente, devido a agropecuária se destacar como principal atividade econômica de Mato Grosso, há influências do setor no modo de pensar e agir profissionalmente dos professores daquela região, que ao estarem inseridos nessa realidade muito marcante, acabam por negligenciar o papel dos seres humanos e suas atividades como parte integrante do ambiente e, desse modo, sujeitos às consequências do desequilíbrio ambiental que ocasionam.

Ressalta-se, ainda, que a compreensão de meio ambiente como sistema, demonstrada por alguns dos professores catarinenses, não se apresenta apenas pela compreensão de conceitos científicos, como, neste exemplo, do conceito de cadeia alimentar. Porém, justamente pelos sujeitos se enxergarem como parte do meio ambiente, dos problemas que podem acontecer com ele e, desse modo, serem capazes de se distanciar do objeto para analisa-lo e pensar em soluções. Alguns professores contextualizaram sobre contaminações ambientais por agrotóxicos em sua realidade, a partir de suas experiências de vida. Neste caso, observa-se relatos tanto de professores catarinenses como de professores mato-grossenses:

Você acredita que, em Campo Verde, mesmo com o sistema de pulverização fechado dos aviões agrícolas que passavam sobre o meu bairro..., fechado, afetavam os pés de fruta de conde e de abacateiro, que depois acabei cortando porque eu fiz uma casa em cima. As folhas dessas árvores ficavam albinas só de passarem os aviõezinhos. Tudo fechado. Só de passar.... E era só chegar época de plantio das lavouras, eu percebia isso! E o pé de mamoeiro ficava muito esquisito! Eu creio que não seja doença não, ficava encarquilhado no broto. Imagina com esse temporal aqui [descrito no texto] (P-6-APEC/MT, grifo nosso). 
Por exemplo, eu uma vez fui em Urubici e aí nós chegamos muito cedo. A gente saiu de madrugada daqui para fazer um trabalho de pesquisa lá e eu estacionei o carro perto de um pomar de maçã e deixei umas frestas no vidro e falei para os bolsistas [que me acompanhavam]: "vamos descansar um pouco. A gente ainda tem uma hora e pouco até a abertura do evento". [...]. Acordamos com o carro branco de veneno, a gente tossindo, passamos o dia inteiro muito ruins... e o grande problema dessas intoxicações é que elas não dão sinais de que foi do veneno. Você chega com sintomas que pode ser de qualquer coisa. [...] (P-3-AEC/SC, grifo nosso).

Inclusive eu mostrei essa semana para os alunos, essa revista aqui que não tem nada a ver com agrotóxicos, pois é uma revista da educação, de 2012. E ela já trazia, aqui, esse emblema de que o brasileiro consumia 5,2 litros de agrotóxicos por ano. E isso contando a população ribeirinha da Amazônia que nem sabe o que é agrotóxico. Se for tirar eles, [a média nacional] vai para mais de sete litros. Então, assim, eu digo que isso aqui é usado tudo de forma inadequada, sem necessidade nenhuma dentro de um programa de controle de doenças (P-10-APEC/SC, grifo nosso).

Pelas falas acima, observa-se que há uma desconfiança sobre os efeitos que os produtos químicos utilizados na agricultura podem ocasionar em organismos não alvos, como outros vegetais ou animais. A dúvida foi frequente entre os entrevistados e pode denotar indícios iniciais de transição da racionalidade instrumental para uma racionalidade menos objetiva e mais questionadora da realidade - nesse caso, a racionalidade socioambiental.

A possibilidade desta transição demonstra-se em fase ainda mais avançada em sujeitos que, ao analisarem o acidente rural de Lucas do Rio Verde/MT, observaram-no pelas influências das dimensões política, econômica e social, aliada a dimensão ambiental. Estes sujeitos (P-9 e P-3, ambos AEC/SC) manifestaram, a nosso ver, uma racionalidade de enfrentamento à racionalidade instrumental, exemplificada, neste trabalho, pela racionalidade crítico-emancipatória ao explicitarem suas compreensões, conforme se observa nos fragmentos:

Eu acho que [os desdobramentos para uma situação como essa] depende do processo educacional, do processo de movimentação e de mobilização social para que a gente possa interpretar isso. Porque você vai ter de diferentes formas, como o próprio filme [Nuvem de veneno] mostra, né? Nas áreas de assentamento teve uma resposta aí imediata, né? De mobilização. Na área da cidade isso fica meio diluído, né? Porque eu acho que é muito colocado essa ideia do que é saúde. Eu acho que entra essa questão do que é saúde e do que é agricultura. De como as pessoas se mobilizam, enfim, como elas se movimentam. [...]. Eu acho que essas questões são bem importantes de serem discutidas. Uma pena, na minha visão, que eu acredito, é que isso passa por uma questão muito mais ideológica, né? [...]. Para mim, essa questão do agrotóxico, ela é muito complexa. Os vieses das dimensões que ele toma porque daí envolve a questão do desenvolvimento; do que isso pode trazer na relação homem, natureza, sociedade (P-9-AEC/SC, grifo nosso).

Hoje, para mim, [o impacto oriundo das atividades agrícolas] é o maior problema que o Brasil enfrenta em termos, inclusive, de saúde pública. Porque o impacto que essa abertura de fronteira dá, ele é de ordem social; porque nesses locais acaba tendo uma venda de pequenas propriedades. Enfim, as pessoas, pequenos agricultores, não conseguem se sustentar mais e acabam vendendo a terra e indo para cidade, para subempregos para viver como puderem viver. [...] [O Brasil] é um país simplesmente sem barreiras para transgênicos, sem barreiras para agrotóxicos. [...]. E não tem, infelizmente, quem regulamente isso. Existem leis, existem princípios, existem ministérios, mas existe um poder subliminar muito estranho, onde os grandes fabricantes, eles ocupam cadeira de voto em conselhos onde eles não poderiam estar 
participando. Uma delas é o CTNBio [Comissão Técnica Nacional de Biossegurança] que controla os transgênicos, por exemplo, e a gente come há anos e não se sabe a gravidade, a periculosidade desses produtos. Eu acho, hoje, [esse é] o maior desafio para a sobrevivência do povo brasileiro, da humanidade até, pois o mundo é um só (P3-AEC/SC, grifo nosso).

O primeiro professor (P-9) demonstrou estar informado tanto sobre o acidente químico em questão quanto aos perigos das contaminações pelos agrotóxicos, citando vídeos documentários (Nuvens de veneno e $\mathrm{O}$ veneno está na mesa ${ }^{7}$ ) e relatórios (Dossiê ABRASCO sobre uso de agrotóxicos no Brasil) que retratam sobre a realidade do uso de agrotóxicos no Brasil. Ele interpreta que o fato ocorrido em Lucas do Rio Verde/MT não pode ser avaliado como um acidente, pois tais condições nem deveriam ser consideradas como seguras para a aplicação de agrotóxicos. Relaciona o fato ao modelo de sistema produtivo neoliberal adotado atualmente e destaca o papel da sociedade e da participação democrática para a discussão de temas controversos como este (o uso de agrotóxicos nas lavouras brasileiras). Já P-3, apontou os efeitos tóxicos dos produtos aplicados, as consequências às populações que, por vezes, não sabem ou não tem noção do que estes produtos podem provocar e acredita que as empresas se aproveitam de dados que não comprovam a contaminação dos ambientes para alegarem a segurança de seus produtos agrícolas comercializados.

Percebe-se que estes dois sujeitos, professores com mais de quinze anos de magistério e atuantes na formação de técnicos agrícolas fundamentada na perspectiva agroecológica, não buscaram olhar para a situação do acidente rural à procura de culpados, mas refletiram sobre a necessidade ou não do uso de agrotóxicos no desenvolvimento das atividades agrícolas, situando-o como uma "escolha" adotada pela sociedade sob forte influência do modelo político e econômico vigente. Tal comportamento reflexivo indica um olhar sócio histórico e existência de uma consciência crítica (FREIRE, 2005) diante de um problema que envolve dimensões variadas, como política, social e ambiental.

Assim, das racionalidades expressas na análise dos sujeitos, em relação a ocorrência do acidente rural de Lucas do Rio Verde/MT, percebe-se que os professores que atuam com os princípios da agroecologia se aproximaram mais de racionalidades de enfrentamento à instrumental, isto é, racionalidades críticas e que vislumbraram a dimensão socioambiental e política ao analisar os problemas vivenciados. Isto pode se justificar pelas próprias características intrínsecas desse campo de conhecimento transdisciplinar (GLIESSMAN, 2000), que compreende que os impactos ambientais não provêm somente de uma crise científico-tecnológica, mas das forças econômicas e relações sociais que legitimam tal modo de produção (LEFF, 2002). Por sua vez, os professores formadores de cursos técnicos em perspectiva da agricultura em larga escala apresentam discursos ora associados à racionalidade instrumental, ora falas (que denotam ser "insights", uma vez que ainda não se trata de um pensamento de total convicção e justificativas fundamentadas) relacionadas à racionalidade socioambiental.

\footnotetext{
7“Nuvens de veneno" (23 minutos) é um documentário dirigido por Beto Novaes, lançado em 2013, que expõe as preocupações com as consequências do uso de agroquímicos no ambiente, especialmente, na saúde do trabalhador. Já “O veneno está na mesa" (49 minutos), dirigido por Silvio Tendler, aborda sobre como a Agricultura proveniente da Revolução Verde e suas técnicas suplantou a agricultura tradicional e vem modificando o ambiente e a vida da população devido as consequências do uso de agrotóxicos. Em 2014 foi lançado o segundo volume do documentário (70 minutos) que avança na abordagem do modelo agrícola nacional atual ao apresentar experiências agroecológicas como alternativa para a produção de alimentos saudáveis e de menor impacto ao ambiente.
} 


\section{CONSIDERAÇÕES FINAIS}

No atual mundo globalizado em que as informações são rapidamente compartilhadas e, até mesmo estão arriscadas a serem difundidas com conceitos errôneos, o papel da educação e do professor torna-se fundamentais. A discussão de temáticas do cotidiano da sociedade, que são repletos de conceitos científicos e exigem a tomada de decisão por parte do Estado é primordial no ambiente escolar em seus mais diversos níveis de ensino.

Beck (2011) acredita que vivemos uma segunda fase da modernidade, denominada modernidade reflexiva. Nela, o desenvolvimento da ciência e da técnica não pode dar conta da predição e controle dos riscos que contribuiu para criar e isto exige uma nova postura da sociedade: que compreenda essa realidade e seja capaz de promover a segurança ambiental e da própria vida dos seres humanos. Com isto, é necessário que a tomada de decisão, antes tecnocrática e unicamente de posse dos especialistas, seja participativa ao considerar também a opinião popular. Por isso a importância da discussão de questões sociocientíficas no ambiente escolar, dentre elas, o debate sobre os riscos e incertezas científicas envolvidos na elevada utilização de agrotóxicos no Brasil.

Neste trabalho, fazendo uso do jogo de palavras com a campanha midiática "Agro é tudo", reconhecemos que as atividades produtivas do agronegócio são "tech" (tecnológicas) devido a todos os processos e procedimentos técnicos e científicos envolvidos. Desde o advento da Revolução Verde, no século passado, com o desenvolvimento da mecanização agrícola, insumos químicos e biotecnologia, a agricultura atingiu um lugar de destaque no desenvolvimento econômico brasileiro. Entretanto, o "Agro ser tech" não garante a segurança do meio ambiente ou da saúde humana. Evidenciamos que o uso dos processos tecnológicos acaba por demonstrar o controle do ser humano sobre a natureza e fornecer uma falsa garantia de controle dos riscos oriundos desses processos. Assim, o "Agro pode ser tech", mas nem sempre o "Agro é pop". E quando é "pop", para quem é? Observamos que o sistema produtivo neoliberal influencia fortemente em prol do enriquecimento de classes sociais específicas e detrimento de outras e ao privilegiar as questões econômicas e desconsiderar problemas ambientais e sociais que as atividades agrícolas podem ocasionar.

Ao analisarmos as compreensões de professores formadores de técnicos agrícolas sobre o uso de agrotóxicos, foi possível identificar quatro tipos de racionalidades que, certamente, influenciam em suas práticas docentes. A racionalidade instrumental, que é a predominante na sociedade, tem influenciado negativamente a formação do técnico agrícola ao privilegiar concepções de que o ser humano possui total domínio e controle sobre os riscos oriundos das atividades tecnocientíficas. Já a racionalidade econômica é aquela que privilegia as questões financeiras em detrimento às demais dimensões. Aqui, ela foi exemplificada pelo pensamento de que os riscos e possíveis prejuízos provocados pelos agrotóxicos são válidos para garantir a produção agrícola em larga escala e a economia do país.

A presença dessas racionalidades no ensino para a formação de técnicos agrícolas faz com que estes profissionais não questionem sobre a necessidade do uso de produtos químicos nas lavouras, por exemplo. E, em relação à quantidade destas substâncias utilizadas, acreditem na existência de um paradigma do "uso seguro" de agrotóxicos, uma vez que os próprios órgãos reguladores estabelecem a dosagem letal de cada um deles à saúde humana e de animais (PERES; MOREIRA; DUBOIS, 2003), desconsiderando, por muitas vezes, os efeitos tóxicos e o potencial de acumulação em longo prazo, tanto nos organismos vivos quanto no meio ambiente. 
Acreditamos que, ao considerar as outras duas racionalidades alternativas à racionalidade instrumental (socioambiental e crítico-emancipatória), o sujeito seja capaz de despertar sua consciência crítica em questionamentos sobre situações de sua realidade, que os auxiliarão na transformação dela: O quê? Por quê? Como? Para quê? Por quem? Para quem? Contra quê? Contra quem? A favor de quem? A favor de quê? No caso específico deste trabalho, tais indagações se referem à (elevada) utilização de agrotóxicos no Brasil e o não reconhecimento das ameaças que estes representam à saúde humana e ambiente.

Ao considerarmos dois modelos de ensino para formação de técnicos agrícolas, um baseado na perspectiva agroecológica e outro fundamentado em princípios do agronegócio, evidenciou-se que os cursos técnicos em Agroecologia (de instituições públicas catarinenses), pelas compreensões de seus professores formadores, demonstram menor alinhamento com características da racionalidade instrumental. Estes sujeitos, ao refletirem sobre o elevado uso de agrotóxicos nas atividades agrícolas, apresentaram compreensões amplas - por considerarem aspectos econômicos, sociais e políticos envolvidos na situação - e críticas - ao vislumbrarem a necessidade de romper com o modelo agrícola vigente de alta dependência de insumos externos à produção.

Já os professores atuantes em cursos técnicos fundamentados em princípios do agronegócio (de instituições mato-grossenses e catarinenses) demonstraram se encontrar em uma transição de racionalidades: ora manifestaram discursos associados à racionalidade instrumental, ora falas (que denotam ser "insights", uma vez que ainda não se trata de um pensamento de total convicção e justificativas fundamentadas) relacionadas à racionalidade socioambiental. O conflito do sujeito em conviver com várias racionalidades faz parte do processo de "ser mais" (FREIRE, 2005) - do despertar de sua consciência para a curiosidade epistemológica a fim de compreender a realidade efetiva vivenciada (alcance da consciência crítica) e do reconhecimento de seu papel nas relações dialógicas com os outros.

Por fim, entendemos que na formação do técnico agrícola (especificamente) e na sociedade em geral (pensando de forma mais ampla) é necessário a adoção de uma racionalidade para além da instrumental; é preciso uma racionalidade crítica que não supervalorize os conhecimentos e ações técnicas, que discuta o modelo de ciência adotado, que questione o poder de decisão das políticas públicas somente aos especialistas (tecnocracia), que considere as esferas social, ecológica e cultural, juntamente com a esfera científica, para a tomada de decisão sobre processos de impactos provenientes das atividades antrópicas.

\section{Referências}

ABRASCO (ASSOCIAÇÃO BRASILEIRA DE SAÚDE COLETIVA). Dossiê: Um alerta sobre os impactos dos agrotóxicos na saúde. São Paulo: Expressão Popular, 2015.

ARANTES, R. R. As verdades inconvenientes que a campanha "Agro Pop" tenta esconder. Ideias na mesa, Brasília: CGEAN/MDS, OPSAN/UnB, 2017. BECK, U. Sociedade de risco: rumo a uma outra modernidade. 2. ed. São Paulo: Editora 34, 2011.

BRASIL. Ato conjunto $n^{\circ} 1$, de 2 de outubro de 2012. Dispõe sobre a aplicação aérea dos ingredientes ativos imidacloprido, clotianidina, fipronil e tiametoxam. Brasília, 2012.

BRASIL. Decreto n. ${ }^{\circ}$ 4.074, de 4 de janeiro de 2002. Regulamenta a Lei no 7.802, de 11 de julho de 1989, que dispõe sobre a pesquisa, a experimentação, [...] e dá outras providências. Brasília, 2002. 
CÂMARA DOS DEPUTADOS. Projeto de Decreto legislativo n. ${ }^{\circ} 809$, de 29 de maio de 2013. Susta a eficácia do Comunicado, de 19 de julho de 2012, do Instituto Brasileiro do Meio Ambiente e dos Recursos Naturais Renováveis. 2013. Disponível em: <http://www.camara.gov.br/proposicoesWeb/fichadetramitacao?idProposicao=563506>. Acesso em: 08 out. 2015.

CÉLERES. Informativo Biotecnologia. Uberlândia, MG: Céleres, 16 dez. 2013. Disponível em: <http://celeres.com.br/wordpress/wp-content/uploads/2013/12/IB13021.pdf>. Acesso em: 15 out. 2014.

CHASSOT, A. Alfabetização científica: uma possibilidade para a inclusão social. Revista Brasileira de Educação, Rio de Janeiro: Anped; Campinas: Autores Associados, n. 22, p. 89100, jan./abr. 2003.

CINTRA, L. Comida química. Super interessante, São Paulo, n. 327, dez. 2013. Disponível em: <http://super.abril.com.br/alimentacao/comida-782481.shtml>. Acesso em: 12 mai. 2015.

DAGNINO, Renato. "Ciência e tecnologia para a cidadania" ou adequação sócio-técnica com o povo? Revista Tecnologia e Sociedade, v. 5, n. 8, 2009.

FREIRE, P. Pedagogia do oprimido. 47. ed. São Paulo: Paz e Terra, 2005.

GIL, A. C. Como elaborar projetos de pesquisa. 5. ed. São Paulo: Atlas, 2010.

GLIESSMAN, S.R. Agroecologia: processo ecológicos em agricultura sustentável. Porto Alegre: Ed. Universidade UFRGS, 2000.

LAMOSA, R.; LOUREIRO, C. F. B. Agronegócio e educação ambiental: uma análise crítica. Revista Ensaio: Avaliação e Políticas Públicas em Educação, v. 22, n. 83, p. 533-554, 2014.

LAYRAGUES, P. P. A cortina de fumaça: o discurso empresarial verde e a ideologia da racionalidade econômica. São Paulo: Annablume, 1998.

LEFF, E. Agroecologia e saber ambiental. Agroecologia e desenvolvimento rural sustentável, Porto Alegre, v. 3, n. 1, p. 36-51, 2002.

LEFF, E. Racionalidade Ambiental: a reapropriação social da natureza. Rio de Janeiro: Civilização Brasileira, 2006.

LOUREIRO, C. F. B. Trajetória e fundamentos da educação ambiental. São Paulo: Cortez, 2004.

LÜDKE, M.; ANDRÉ, M. E. D. A. Pesquisa em Educação: abordagens qualitativas. EPU: São Paulo, 1986.

MARCUSE, H. Industrialização e Capitalismo na obra de Max Weber. In: MARCUSE, H. Cultura e Sociedade II. São Paulo: Paz e Terra, 1998. p. 113-136.

MIRANDA, A. C. de et al. Neoliberalismo, uso de agrotóxicos e a crise da soberania alimentar no Brasil. Ciênc. saúde coletiva, Rio de Janeiro, v. 12, n. 1, p. 7-14, 2007.

PACHECO, E. (Org). Institutos federais: uma revolução na educação profissional e tecnológica. Fundação Santinlana/Moderna: Brasília, São Paulo, 2011.

PERES, F.; MOREIRA, J. C.; DUBOIS, G. S. Agrotóxicos, saúde e ambiente: uma introdução ao tema. In: PERES, F.; MOREIRA, J. C. (Orgs.). É veneno ou é remédio? Agrotóxicos, saúde e ambiente. Rio de Janeiro: Fiocruz, 2003. p. 21-41. 
PIGNATI, W. A.; MACHADO, J. M. H.; CABRAL, J. F. Acidente rural ampliado: o caso das "chuvas" de agrotóxicos sobre a cidade de Lucas do Rio Verde. Ciênc. saúde coletiva, Rio de Janeiro, v. 12, p. 105-114, 2007.

PORTO, M. F.; SOARES, W. L. Modelo de desenvolvimento, agrotóxicos e saúde: um panorama da realidade agrícola brasileira e propostas para uma agenda de pesquisa inovadora. Rev. bras. saúde ocup., São Paulo, v.37, n.125, p. 17-31, 2012.

SAUVÉ, L. Uma cartografia das correntes em educação ambiental. In: SATO, M.; CARVALHO, I. C. M. Educação Ambiental: pesquisa e desafios. Porto Alegre: Editora Penso, 2005. p. 17-44.

SILVEIRA, A. V. T.; ANTONIOSI-FILHO, N. R. Proposta de alternativas menos tóxicas para ingredientes ativos de agrotóxicos no mercado brasileiro. Pestic. R. Ecotoxicol. Meio Amb, Curitiba, v. 23, p. 11-24, 2013.

SOUZA, L. C. A. B. A problematização do Princípio da Precação na formação do técnico agrícola: reflexões para o enfrentamento da racionalidade instrumental a partir de uma questão sociocientífica. 2016. 351 f. Tese (Doutorado em Educação Científica e Tecnológica) - Curso de Pós-Graduação em Educação Científica e Tecnológica, Universidade Federal de Santa Catarina, Florianópolis, 2016.

\section{Agradecimentos}

À CAPES, pela concessão de bolsa no Programa de Doutorado Sanduíche no Exterior (Processo ${ }^{\circ}$ 99999.002910/2014-04). Ao Fundo de Apoio à Manutenção e ao Desenvolvimento da Educação Superior de Santa Catarina (FUMDES/SC) pelo apoio e financiamento desta investigação a partir da concessão de bolsa de estudos em nível de doutorado (2014-2016). Aos onze professores que concederam as entrevistas, objeto de pesquisa deste estudo. 